\title{
AnÁlise de Jogos de PalaVRas nas legendas de TÁ CHOVEndo HAMBÚRGUER 2
}

AdAuRi BREZOLIN*

KaMYLA OHASH $* *$

\section{Resumo}

Neste artigo, analisamos a tradução de jogos de palavras nas legendas da animação Tá chovendo hambúrger 2. Vinte e três jogos de palavras foram selecionados, comparados com as legendas (português brasileiro) e analisados, objetivando verificar se do ponto de vista idiomático e pragmático os efeitos haviam sido, de alguma forma, preservados. Nossos resultados mostram que 20 jogos de palavras foram traduzidos por outros jogos de palavras, um foi traduzido por recurso retórico relacionado de aliteração e dois não foram traduzidos por outros jogos de palavras. Constatamos que, de modo geral, o tradutor manteve os efeitos idiomático e pragmático do original.

PalaVRas-Chave: Tradução audiovisual. Jogos de palavras. Humor. Legendagem.

\section{INTRODUÇÃO}

Tradicionalmente, jogos de palavras (JPs) nem sempre receberam a atenção dispensada a outros tipos de criações humorísticas como, por exemplo, as piadas. Porém, nos últimos anos, tem aumentado o número de trabalhos que abordam esse fenômeno do ponto vista linguístico, psicolinguístico ou interlinguístico. Nesses trabalhos se analisam, sobretudo, as dificuldades que envolvem sua transposição de uma língua para outra (DORE, 2010), em nossa análise trata-se do inglês para o português brasileiro.

* $\quad$ Doutor em Letras pela Universidade de São Paulo (USP), São Paulo, SP, Brasil. E-mail: brezolinadau@yahoo.com.br

** Bacharel em Letras, Língua Estrangeira, da Escola de Comunicação, Educação e Humanidades, da Universidade Metodista de São Paulo, São Bernardo do Campo, São Paulo, Brasil. E-mail:kamy.ohashi@gmail.com 
O aumento no interesse pela tradução de JPs pode ser observado pelas várias publicações que versam sobre o tema, sejam ensaios, artigos, trabalhos de conclusão de curso de graduação e especialização (GOTTLIEB, 1997; DORE, 2010; GIORGADZE, 2014; TAGNIN, 2015; OHASHI, 2018), ou dissertações e teses de programas de pósgraduação (SILVA, 2015; TAGNIN, 2015).

Este artigo, recorte de um trabalho de conclusão de curso, tem como corpus de estudo a comédia de animação Tá chovendo hambúrguer 2 (Cloudy with a chance of meatballs 2). A escolha desse corpus se deu pelo fato de que seu humor é construído a partir de vários elementos, em especial de JPs, os quais, em sua maioria, estão intimamente ligados a algum tipo de alimento e à imagem apresentada. O filme (CLOUDY..., 2013), com direção de Cody Cameron e Kris Pearn e roteiro de John Francis Daley e Jonathan M. Goldstein, trata da aventura de Flint Lockwood e seus amigos na tentativa de salvar o mundo de comidanimais, mutantes e perigosas. A partir das falas originais, selecionamos 23 trechos com JPs, todos criados a partir de nomes de alimentos e termos relacionados à alimentação.

Para nossas análises, recorremos, principalmente, aos conceitos de JP e às estratégias de tradução de Delabastita $(1996,2007)$ e Gottlieb (1997), correlacionados a diversas teorias de humor, entre elas a teoria da incongruência (MORREALL, 1983), bem como às considerações sobre tradução audiovisual de Diaz-Cintas (2005) e Chiaro (2009). Dadas as características intrínsecas dos JPs e da legendagem, consideramos o pressuposto de que sua tradução impõe desafios maiores aos tradutores, uma vez que envolvem tanto estruturas linguísticas associadas à linguagem verbal e a não-verbal como restrições de tempo e espaço. Nossos objetivos são, portanto, verificar os JPs presentes na fala original do filme, classificá-los quanto ao tipo e compará-los com as legendas e, ainda, analisar as estratégias de tradução empregadas pelo tradutor. Se necessário, uma tradução mais adequada será sugerida nos casos em que o JP não tiver sido preservado de algum modo. 


\section{JOGOS DE PALAVRAS}

Segundo Delabastita (1996):

Jogo de palavras é o nome genérico para vários fenômenos textuais nos quais características da língua utilizada são exploradas com a intenção de provocar um confronto comunicativo significativo de duas (ou mais) estruturas linguísticas com formas mais ou menos similares e sentidos mais ou menos diferentes. (p. 128, tradução nossa) $)^{1}$.

A seguir, apresentamos, então, algumas maneiras pelas quais um idioma pode ser explorado para a criação de JPs. Mesmo considerando a possibilidade de que eles ocorram em todas as línguas, sua tradução torna-se ainda mais desafiadora, uma vez que os JPs são gerados a partir de estruturas linguísticas particulares, às quais dificilmente encontraremos correspondentes diretos em outro idioma.

Os recursos empregados para criar JPs, em geral, são classificados como homonímia, homofonia, homografia e paronímia (GOTTLIEB, 1997; TAGNIN, 2005). Delabastita (1996) também considera esses recursos e os amplia, sugerindo cinco categorizações:

a. Estrutura fonológica e grafológica, subdividida em:

- Homonímia: palavras com grafia e pronúncia idênticas e significados diferentes, por exemplo: caro (dispendioso) e caro (prezado);

- Homografia: palavras com grafia idêntica e pronúncia e significado diferentes, por exemplo: colher (utensílio) e colher (verbo);

- Homofonia: palavras com pronúncia idêntica e grafia e significado diferentes, por exemplo: nós e noz;

- Paronímia: palavras com grafia e pronúncia semelhantes e significados distintos, por exemplo: infringir e infligir.

b. Estrutura lexical polissêmica: segundo Delabastita (1996), a língua dispõe de palavras com grafia e pronúncia idênticas e vários significados, por exemplo: pé (parte do corpo humano) e pé (exemplar de uma planta). Amaral (2015) salienta 
a importância de distinguirmos as palavras homônimas, com significados independentes, e as polissêmicas, com significados relacionados. Em nosso exemplo, os dois usos da palavra pé remetem ao conceito de base, sustentação.

c. Estrutura morfológica: muitos processos de formação de palavras podem ser utilizados na criação de JPs (DELABASTITA, 1996). Dentre eles, destacamos os neologismos, cujos processos de formação variam dos fonológicos e sintáticos aos semânticos (ALVES, 1990). Neste artigo, daremos destaque ao processo conhecido, em inglês, como portmanteau word ou blend(ing), um tipo de JP, de acordo com Davis (1997). Em português, esse fenômeno pode receber várias denominações: cruzamento vocabular; palavra portmanteau; contaminação; palavra-valise (ALVES, 1990) e, ainda, mistura e blend lexical (GONÇALVES, 2003). Neste trabalho, optamos pelo termo palavra-valise, ou seja, um tipo de redução em que "duas bases são privadas de parte de seus elementos para constituírem um novo item léxico: uma perde sua parte final e outra, sua parte inicial", por exemplo, brasiguaio (brasileiro + paraguaio), cantriz (cantora + atriz) (ALVES, 1990, p. 69) ou a fusão de duas palavras que servem de "input à formação de uma terceira," caracterizada pela "interseção de bases", como em portunhol (português + espanhol), por exemplo (GONÇALVES, 2003, p. 149-150).

d. Estrutura sintática: a "gramática, muitas vezes, produz frases ou sentenças que podem ser analisadas de mais de uma maneira"2 (DELABASTITA, 2007, p. 603, tradução nossa). Esse fenômeno é conhecido como ambiguidade sintática e caracteriza-se pelo duplo sentido causado pela organização estrutural de uma sentença quando uma sequência de palavras possui mais de uma interpretação. Por exemplo: $O$ vendedor ameaçou o garoto com uma faca, o vendedor ou o garoto segurava uma faca?

e. Estrutura lexical idiomática: refere-se a combinações linguísticas cujo sentido não pode ser depreendido pela leitura 
isolada das palavras que as compõem, devem, para que sejam compreendidas, ser interpretadas de modo metafórico, não literal. Segundo Delabastita (1996) e Veisbergs (1997), JPs são criados a partir dessas estruturas quando há confronto entre uma leitura literal e outra metafórica, incorrendo, assim, na quebra de expectativa por parte do leitor. Por exemplo, chutar o pau da barraca é uma expressão que permite duas leituras: colocar a barraca abaixo (literal) ou perder a paciência (metafórica). Além disso, Veisbergs (1997) argumenta que esses JPs podem, também, apresentar modificações estruturais, como inserções, omissões ou substituições de termos.

Como observado, há várias maneiras de se produzir um JP. Veisbergs (1997) e Chiaro (2006), por exemplo, defendem que ao manipularmos fenômenos linguísticos para a geração de um JP buscase, na maioria das vezes, criar um efeito cômico com a intenção de entreter e atrair a atenção de leitores/ouvintes, sugerindo-nos, então, que o JP seja inseparável do humor.

Gottlieb (1997), salientando a natureza pragmática dos JPs, corrobora a concepção de que uma dupla interpretação por parte do leitor/ouvinte leva-nos à ideia de incongruência, que pode ser o motivo do humor. Segundo Morreall (1983, p. 15), isso se deve ao fato de que o leitor/ouvinte, ao ser exposto a uma situação "inesperada, ilógica ou inapropriada" e, ao sentir-se de certa forma enganado, achará isso engraçado. Para o autor, esse cenário de humor associa-se à teoria da incongruência, visto que vivemos num mundo organizado de acordo com determinados padrões, e sua quebra faz as pessoas rirem. Tagnin (2005, p. 247) acrescenta que é da quebra de convencionalidade que o humor se origina, reforçando, assim, a ideia de incongruência: quando há oposição entre aquilo que se espera que aconteça e aquilo que de fato ocorre.

Em vista disso, o tradutor deverá, então, estar atento às possíveis manipulações linguísticas para a criação de JPs e tentar reproduzi-las da forma mais apropriada. Para tanto, Delabastita (1996) nos oferece algumas sugestões, conforme veremos adiante. 


\section{ESTRATÉGIAS DE TRADUÇÃO}

Ao tratar de tradução audiovisual (TA), Chiaro (2009) alega que os produtos audiovisuais são polissemióticos e complexos, isto é, operam simultaneamente em dois níveis diferentes e desfrutam de inúmeros códigos, visuais e acústicos, combinados com a finalidade de criar uma unidade. Portanto, mesmo que a tradução opere apenas no nível verbal, há uma ligação indissociável com o nível visual, o qual não pode ser modificado.

A legendagem, uma das modalidades de TA, prioriza o canal visual, na medida em que se caracteriza pela transposição de texto falado para escrito. Diaz-Cintas (2005) esclarece que o trabalho de legendagem exige frequentemente que o texto escrito seja condensado, devido a restrições técnicas de espaço e tempo, ou seja, existem limites de caracteres por linha e limitações de permanência na tela para que $o$ espectador possa ler e desfrutar do filme.

No âmbito audiovisual, portanto, como apresentam uma natureza semiótica, os JPs podem aparecer por meio de diálogos (entonação e prosódia), diálogos combinados com informação não-verbal, visual ou textos escritos na tela (placas, anúncios, identificação de pessoas, dentre outros) (GOTTLIEB, 1997, p. 210). Em todos esses casos ressaltamos que o suposto confronto entre duas leituras, criado pelo JP, ocorre simultaneamente entre os níveis linguístico, visual e acústico, como dissemos, trata-se da criação de uma unidade indissociável entre o verbal e o não-verbal.

Para a tradução de JPs, Delabastita (1996) sugere que se um JP é possível numa língua, também será possível reproduzi-lo em outra; sobretudo, em virtude da existência de fenômenos linguísticos como os citados acima, homonímia, polissemia, paronímia, dentre outros, comuns a vários idiomas. Delabastita (1996) e Gottlieb (1997) propõem algumas estratégias para a tradução de JPs.

A seguir, há oito estratégias de tradução ${ }^{3}$ apresentadas por Delabastita:

1. JP $\rightarrow$ JP: o JP presente no texto-fonte é traduzido por outro JP, podendo diferir do significado do original no que diz respeito à estrutura formal, estrutura semântica ou função textual; 
2. JP $\rightarrow$ Não JP: o JP é traduzido por um sintagma que não contém JP. Ele pode manter os dois significados do JP ou selecionar apenas um dos significados e sacrificar o outro;

3. JP $\rightarrow$ RRR: o JP é substituído por um recurso retórico relacionado a ele, objetivando recapturar o efeito do JP original. Dentre esses recursos, estão: repetição, aliteração, rima, ironia, metáfora, paradoxo, entre outros;

4. JP $\rightarrow$ Zero: o trecho em que o JP aparece é omitido na tradução;

5. JP TF $=$ JP TT: o tradutor reproduz o JP do texto-fonte e seu contexto, sem de fato traduzi-lo;

6. Não JP $\rightarrow$ JP: o tradutor acrescenta um JP em partes do texto em que o original não tem JP, como uma maneira de compensar a perda de JPs em alguma outra parte;

7. Zero $\rightarrow$ JP: o tradutor adiciona um material textual totalmente novo que apresenta o JP, essa estratégia também é utilizada como um recurso compensatório;

8. Técnicas editoriais: o tradutor acrescenta paratextos a fim de apresentar soluções diferentes e/ou complementares para o JP.

Ao considerarmos que as estratégias de tradução de Delabastita (1996) se refiram ao tratamento dado a JPs sem distinção do tipo de texto, algumas delas não poderiam ser empregadas em legendas devido às particularidades desse tipo de tradução. As restrições de espaço e a própria disposição das legendas na tela impediriam o emprego de técnicas editoriais; uma nota de rodapé, por exemplo, não poderia ser usada. As restrições de tempo também limitariam o uso de outros recursos (como o compensatório), que não poderiam ser inseridos nem muito antes, nem muito depois da cena em que o JP se mostra relevante em virtude da indissociabilidade do verbal e do não-verbal.

Gottlieb (1997), por sua vez, apresenta estratégias elaboradas a partir da análise da tradução de JPs em material audiovisual. Segundo ele, um JP pode:

1. ser traduzido de forma literal, preservando ou não o efeito humorístico;

2. ser adaptado ao cenário local, à cultura da língua de chegada, para manter o efeito humorístico;

3. ser substituído por um não-JP;

4. não ser traduzido, dando espaço a um diálogo subsequente; 
5. ser inserido em diferentes posições textuais, onde for possível, de acordo com a língua-alvo.

De modo geral, essas estratégias de tradução de JPs se mostram bastante apropriadas à nossa discussão, uma vez que foram detectadas e classificadas a partir da análise de legendas também. Mesmo assim, acreditamos que a estratégia 5, que prevê um recurso compensatório semelhante ao proposto por Delabastita (1996), parece não ser uma estratégia recomendada; em especial pelo aspecto de indissociabilidade entre o verbal e o não-verbal. Sobre isso, Gottlieb (1997, p. 222) menciona que encontrou apenas uma ocorrência de compensação analisando legendas em dinamarquês a partir das falas de um programa humorístico britânico.

Guardadas as limitações de cada proposta, um tradutor pode, então, recorrer a diversos tipos de estratégias diante do desafio de traduzir JPs. A seguir, veremos como os JPs extraídos da comédia de animação em destaque foram transpostos para a língua portuguesa no Brasil.

\section{ANÁLISE DE DADOS}

Nosso corpus constitui-se de 23 JPs encontrados nas falas originais e cotejados com as legendas. Para facilitar a análise, eles foram agrupados de acordo com o recurso empregado para sua criação: estrutura fonológica e grafológica (homofonia e homonímia); estrutura lexical polissêmica; estrutura lexical idiomática e estrutura morfológica.

Nossa apresentação dos dados conta com uma breve contextualização da cena em que aparecem os JPs, os quais serão apresentados em quadros bicolunados, com o trecho da fala original e a tradução da respectiva legenda, seguidos das análises e, caso necessário, de uma sugestão de tradução mais adequada.

\section{ESTRUTURA FONOLÓGICA E GRAFOLÓGICA}

\section{HOMOFONIA}

Flint e seus amigos estão atrás de Barry, um animal-morango, quando acabam em um pequeno rio no meio da mata. Flint, surpreso, 
profere a seguinte frase: There's a leek in the boat! (Quadro 1). Em virtude da homofonia entre leek (alho-poró) e leak (vazamento), a princípio, entende-se que há um vazamento no barco em que estavam, porém a ideia é desconstruída quando aparece um alho-poró no assento do motorista, criando-se, assim, um JP.

QuAdRo 1 - RECURSO EMPREGADO: HOMOFONIA - LEEK/LEAK

\begin{tabular}{|l|l|}
\hline ORIGINAL & LEGENDAGEM \\
\hline Flint: There's a LeEK IN the BOAT! & FLint: Poró Pirata no BARCo! \\
\hline
\end{tabular}

Fonte: Elaborado pelos autores (2019).

$\mathrm{Na}$ legendagem, o tradutor tentou manter o JP utilizando uma das estratégias propostas por Delabastita (1996), substituição do JP por um recurso retórico, na expectativa de preservar o efeito do original. Nesse caso, o recurso retórico de aliteração foi empregado e a consoante $p$ foi repetida. Embora seja uma solução adequada, nossa sugestão reforça essa aliteração:

\section{Flint: Poró piloto pilotando!}

ESTRUTURA LEXICAL POLISSÊMICA

Flint cria um dispositivo que transporta objetos e pessoas para outros lugares, sugerindo que possam ir a Boca Grande mais rapidamente. $\mathrm{O}$ inventor pergunta aos amigos quem gostaria de testar a máquina primeiro, mas eles ficam desconfiados e ninguém toma a iniciativa. Em seguida, Steve procura na mochila algo para comer, encontra um sanduíche com banana e quebra o silêncio com: hungry, supondo que o animal estivesse com fome (Quadro 2). Todavia, Flint entende que Steve anseia pela aventura que iriam ter, pois o vocábulo também apresenta o sentido de algo que a pessoa deseja muito, criando, portanto, o JP. 
QuAdro 2 - RECURSO EMPREGADO: ESTRUTURA LEXICAL POLISSÊMICA - HUNGRY

\begin{tabular}{|c|c|}
\hline ORIGINAL & LEGENDAGEM \\
\hline Flint: All RIGHT, WHO WANTS tO GO FIRST? & FLINT: QUEM QUER IR PRIMEIRO? \\
\hline Steve: Hungry. & SteVe: Fome. \\
\hline Flint: Yes, STEVE, HUNGRY FOR ADVENTURE. & Flint: É, SteVe, FOME DE AVENTURA. \\
\hline
\end{tabular}

Fonte: Elaborado pelos autores (2019).

O JP do original foi mantido na legendagem, uma vez que o termo fome pode significar "desejo de comer" ou "vontade intensa" (AULETE, 2019), o que condiz com a cena em que Steve encontra comida (sentido literal) e os outros entendem que ele deseja participar da aventura (sentido figurado). Desse modo, não sugerimos uma tradução.

Chester V tenta enganar Flint dizendo que as comidanimais são um perigo para a sociedade. No entanto, seus amigos percebem que elas são dóceis e não apresentam perigo algum (Quadro 3). Sam tenta argumentar a favor das comidas e Manny concorda, acrescentando um comentário.

QUADRO 3 - RECURSO EMPREGADO: ESTRUTURA LEXICAL POLISSÊMICA - SWEET

\begin{tabular}{|l|l|}
\hline ORIGINAL & LEGENDAGEM \\
\hline $\begin{array}{l}\text { MANNY: IT IS TRUE. THE DESSERT CREATURES ARE } \\
\text { ESPECIALLY SWEET. }\end{array}$ & $\begin{array}{l}\text { MANNY: É. As SOBREMESAS TÊM } \\
\text { SIDO UNS DOCES. }\end{array}$ \\
\hline
\end{tabular}

Fonte: Elaborado pelos autores (2019).

A polissemia acontece com a palavra sweet, em inglês, que, da mesma forma que doce, em português, pode referir-se a algo "com sabor semelhante ao do açúcar ou do mel" ou a "meigo, carinhoso" (AULETE, 2019). Por causa dessa coincidência, o JP foi traduzido por JP (DELABASTITA, 1996), preservando o mesmo efeito e, portanto, dispensando a necessidade de uma sugestão. 
Antes de chegar à cidade, Flint e seus amigos estão no barco tentando criar estratégias para conseguir salvar Boca Grande, quando o protagonista profere: If we work together, this should be easy as... e Manny completa: pie (Quadro 4). A expressão idiomática easy as pie possui o significado de algo fácil, que não exige esforço (URBAN DICTIONARY, 2019). A construção do JP efetiva-se com a junção da expressão idiomática e com a imagem de um pedaço de torta que aparece na sequência.

QuAdro 4 - ReCurso EMPREGAdo: eStrutura LEXICAL IDIOMÁticA - AS EASY AS PIE

\begin{tabular}{|l|l|}
\hline ORIGINAL & LEGENDAGEM \\
\hline FLINT: IF WE WORK TOGETHER, THIS SHOULD BE & FLINT: TODOS JUNTOS, VAI SER \\
EASY AS... & MAMÃo COM... \\
MANNY: PIE. & MANNY: TORTA. \\
\hline
\end{tabular}

Fonte: Elaborado pelos autores (2019).

Nesse caso, em que a imagem da torta é determinante, o tradutor tentou manter o JP do original adaptando-o à cultura da língua de chegada (GOTTLIEB, 1997) e alterando um dos elementos constituintes da expressão idiomática consagrada, mamão com açúcar, que significa “coisa fácil” (DICIONÁRIO DE EXPRESSÕES, 2019), transformando-a em mamão com torta. Desse modo, o JP foi bastante apropriado e seu efeito humorístico até mesmo mais vigoroso, ao se realizar por meio da quebra de expectativa (TAGNIN, 2005); portanto, não há necessidade de uma sugestão de tradução.

Após verem pedaços de torta no meio da água, Flint e Sam imaginam que terão dificuldade para continuar o percurso e que, assim, estão prestes a entrar em confusão. Isso é indicado pela expressão idiomática to be toast (Quadro 5), em que toast refere-se a "encrencado" (MERRIAM-WEBSTER, 2019). Num primeiro momento, entende-se que esse seja o sentido pretendido (metafórico); no entanto, logo em seguida, aparecem French toasts, rabanadas em português, atribuindo à palavra seu sentido literal (tipo de pão) e, como resultado, gerando o JP. 
QuAdro 5 - RECURSO EMPREGADO: ESTRUTURA LEXICAL IDIOMÁTICA - TO BE TOAST

\begin{tabular}{|l|l|}
\hline ORIGINAL & LEGENDAGEM \\
\hline FLINT: OH, No! WE'RE... & FLINT: VAMOS VIRAR... \\
SAM: TOAST! & SAM: TORRADA! \\
EARL: FrENCH TOAST! & EARL: RABANADA! \\
\hline
\end{tabular}

Fonte: Elaborado pelos autores (2019).

Observamos que o JP foi traduzido de modo literal, sem preservar o efeito humorístico (GOTTLIEB, 1997), pois a legenda, como não permite duas leituras (literal/figurada), deixa de criar um JP como no original, que é, evidentemente, favorecido pela imagem. Na tentativa de gerarmos um JP em português, sugerimos o seguinte:

Flint: Quanta...

Sam: Lasca!

Earl: Estamos lascados!

Dessa forma, recorremos à palavra lasca, que permeia o campo semântico de pedaço, fatia, pão e nos permite lançar mão de lascado, termo que, por sua vez, pode evocar sentidos como "quebrado em lascas" e "encrencado, ferrado" (AULETE, 2019), dentre outros. O uso de lascas (sentido literal), contrapondo-se a lascados (sentido figurado), resulta em um JP gerado, segundo Gottlieb (1997), por meio de adaptação à cultura da língua de chegada, com a preservação do efeito humorístico.

Ainda em direção a Boca Grande e após o diálogo anterior, o grupo se depara, dessa vez, com várias bananas. Steve completa a frase iniciada por Flint: This is totally... bananas, na qual Flint tinha a intenção de proferir: This is totally... nuts (Quadro 6). Ambas as expressões, go bananas e to be nuts indicam que algo é louco, maluco (URBAN DICTIONARY, 2019). O JP é construído a partir da expressão idiomática go bananas e da imagem da fruta apresentada. 
QUADRO 6 - RECURSO EMPREGADO: ESTRUTURA LEXICAL IDIOMÁtICA - BANANAS

\begin{tabular}{|c|c|}
\hline ORIGINAL & LEGENDAGEM \\
\hline FLINT: THIS IS TOTALLY... & Flint: VAMOS TER QUE DESCASCAR... \\
\hline SteVe: Bananas! & Steve: Banana! \\
\hline $\begin{array}{l}\text { FLINT: I WAS GONNA SAY } \\
\text { "NUTS", BUT NOW I'M AFRAID } \\
\text { TO. }\end{array}$ & $\begin{array}{l}\text { FLINT: EU IA DIZER “ABACAXI”, MAS AGORA } \\
\text { NEM ARRISCO. }\end{array}$ \\
\hline
\end{tabular}

Fonte: Elaborado pelos autores (2019).

A legendagem manteve, de certa forma, o JP, pois num primeiro momento reconhecemos descascar banana e descascar um abacaxi como expressões idiomáticas típicas da língua portuguesa. No entanto, elas não compartilham o mesmo sentido metafórico, uma vez que descascar banana refere-se à prática da masturbação masculina e descascar um abacaxi a resolver problema ou enfrentar situação difícil ou desagradável (AULETE, 2019). Assim, inferimos que a opção por banana se deu, forçosa e inevitavelmente, pelo aparecimento da fruta na tela. Embora essa solução nos pareça satisfatória, sugerimos a seguinte:

Flint: Que loucura, aqui só tem...

Steve: Banana!

Flint: É... vamos todos nos embananar.

Nossa sugestão, embananar-se, meter(se) em dificuldades, problemas, complicações (AULETE, 2019), reflete uma escolha claramente motivada pela importância da combinação entre texto e imagem.

Já em Boca Grande, o grupo, ao se defrontar com diversos pontos da cidade danificados e envoltos por alimentos, avista uma suposta casa coberta por teias de queijo, produzidas pela comidanimal queijaranha. $\mathrm{Na}$ eventualidade de ainda restar algum sobrevivente dentro da construção, Earl toma a iniciativa e grita: I'm gonna cut the cheesel Vou cortar esse queijo (Quadro 7). Em seguida, Earl aparece cortando o queijo e ouvem-se sons de gases intestinais. O JP, produzido em inglês pela dupla leitura possibilitada por to cut the cheese, cortar o queijo 
em pedaços ou soltar gases, reforça, uma vez mais, a combinação de imagem e som.

QuAdRo 7 - ReCURSO EMPREGADO: ESTRUTURA LEXICAL IDIOMÁTICA - TO CUT THE CHEESE

\begin{tabular}{|l|l|}
\hline ORIGINAL & LEGENDAGEM \\
\hline EARL: StAND BACK, EVERYBODy. I'M GONNA & EARL: AfASTA, GENTE. VOU \\
CUT THE CHEESE. & CORTAR ESSE QUEIJO. \\
[FART SOUND] & [SOM DE GASES] \\
EARL: UH... THAT WAS THE CHEESE. & EARL: FoI O QUEIJO. \\
\hline
\end{tabular}

Fonte: Elaborado pelos autores (2019).

Dada a impossibilidade de realizar uma tradução que mantivesse os aspectos tanto idiomáticos quanto pragmáticos presentes no JP, criado a partir da dupla leitura de to cut the cheese (fatiar o queijo e soltar gases), o tradutor optou por uma solução literal, preservando, assim, apenas o aspecto pragmático, ou seja, o efeito humorístico. Isso se deu pela dupla interpretação de Foi o queijo, pois podemos entender que os gases foram por causa do queijo que Earl havia comido ou que o queijo é que havia soltado os gases. Na tentativa de explicitar a situação (de que foi Earl quem soltou os gases), sugerimos o seguinte:

Earl: Afasta, gente, comi muito queijo, tô com todo o gás, vou cortar...

[som de gases]

Earl: Foi o queijo.

Embora a expressão estar com todo o gás signifique "estar disposto, com energia", seu uso, precedido por Afasta, gente, comi muito queijo, propicia uma leitura metafórica, ainda mais quando se ouve o som de gases, criando-se, assim, um JP. Além disso, há o acréscimo de vou cortar como referência à interpretação literal de to cut the cheese, que será resgatada pela cena em que Earl, de fato, corta as tiras de queijo. É desnecessário dizer que, nesse caso, Foi o queijo passa a ser compreendido como Foi por causa do queijo que comi. 
Flint e seus amigos estão atrás de Barry no rio e, de repente, encontram-se diante de uma queda d'água. Earl, que conduzia o bote, pede que se segurem e anuncia: This ain't gonna be no picnic, que metaforicamente exprime a ideia de que "algo não é fácil, agradável ou prazeroso" (Quadro 8). Na sequência, eles caem dentro de um coco gigante. O JP se cria pelo fato de que, como as personagens deixaram para trás várias comidanimais, não terão mais o que comer, ou seja, no picnic, interpretação literal da expressão.

QuAdro 8 - Recurso EMPREgAdo: ESTRUTURA LEXICAL IDIOMÁtiCA - TO BE NO PICNIC

\begin{tabular}{|l|l|}
\hline ORIGINAL & LEGENDAGEM \\
\hline EARL: HOLD ON, EVERYBODY! THIS & EARL: SEGURA, GENTE! COCO É DOCE, \\
AIN'T GONNA BE NO PICNIC. & MAS É DURO. \\
\hline
\end{tabular}

Fonte: Elaborado pelos autores (2019).

$\mathrm{O}$ tradutor, tentando recriar o JP, aproveita a imagem do coco, explorando duas possíveis características da fruta: doçura e dureza. No entanto, Coco é doce, mas é duro nos remete prontamente à expressão Rapadura é doce, mas não é mole não, soando artificial demais. Nossa sugestão é:

\section{Earl: Segura, gente! Coco é doce, mas não é mole não.}

Essa solução revela duas estratégias que se complementam: adaptação de JP à cultura da língua de chegada (GOTTLIEB, 1997) e, ao nos basearmos num fraseologismo já existente e o modificarmos, podemos classificá-la em transformação estrutural por substituição (VEISBERGS, 1997). Resultado que, a nosso ver, recria um JP e preserva seus aspectos idiomáticos e pragmáticos.

Flint e seu pai, Tim, reúnem comidanimais para tentar socorrer seus amigos que foram capturados por Chester V. Como Tim é pescador, ocorre-lhes a ideia de construírem uma vara de pesca gigante para poder lançar Flint e Barry até o local onde Chester V está. Flint questiona se seria fácil lançá-los e seu pai responde que sim, usando uma expressão 
idiomática: Should be a piece of cake; em seguida, aparece um pedaço de bolo (Quadro 9). Cria-se, desse modo, um JP que mais uma vez, além de combinar o verbal e o não-verbal, se realiza por meio de duas leituras, uma metafórica e outra literal.

Quadro 9 - Recurso empregado: estrutura leXicAl idiomÁtica - A PIECE OF CAKE

\begin{tabular}{|l|l|}
\hline ORIGINAL & LEGENDAGEM \\
\hline TIM: SHOULD BE A PIECE OF CAKE. & TIM: VAI SER BOLINHO. \\
\hline
\end{tabular}

Fonte: Elaborado pelos autores (2019).

Em função dessa combinação texto/imagem, o tradutor optou por vai ser bolinho; fazendo referência à expressão não é bolinho, que significa "coisa difícil" (NOGUEIRA\& SILVA, 2017). De certa maneira, um JP foi gerado a partir do processo de transformação estrutural (VEISBERG, 1997), especialmente com a supressão da negativa. Como Nogueira e Silva (2017) sugerem que essa expressão seja mais utilizada na zona rural do centro-oeste brasileiro, e provavelmente desconhecida por muitas pessoas, sugerimos o seguinte:

\section{Tim: Vai ser tão fácil quanto tirar bolo de criança.}

Desse modo, recorremos à expressão idiomática tão fácil quanto tirar/roubar doce de criança e, pelo processo de transformação estrutural por substituição (VEISBERG, 1997), trocamos doce por bolo; resgatando, portanto, sua associação com a imagem exibida e criando um JP.

\section{ESTRUTURA MORFOLÓGICA}

Ao longo da obra cinematográfica aparece uma série de comidanimais, criações a partir da junção de algum tipo de alimento e um animal (Quadro 10). Conforme vimos, trata-se de casos de palavrasvalise. 
QuAdro 10 - RECURSO EMPREGAdO: ESTRUTURA MORFOLÓGICA - PALAVRAS-VALISE

\begin{tabular}{|l|l|}
\hline ORIGINAL & LEGENDAGEM \\
\hline BANANOSTRICH (BANANA + OSTRICH) & BANANESTRUZ (BANANA + AVESTRUZ) \\
\hline CANTELOPE (CANTELOUPE + ANTILOPE) & MELANTÍLOPE (MELÃO + ANTÍLOPE) \\
\hline CHEESPIDER (CHEESEBURGER + SPIDER) & QUEIJARANHA (QUEIJO + ARANHA) \\
\hline FLAMANGO (FLAMINGO + MANGO) & FLAMENGA (FLAMINGO + MANGA) \\
\hline FOODICIDE (FOOD + SUICIDE) & NUTRICÍDIO (NUTRIENTE + SUICÍDIO) \\
\hline FOODIMAL (FOOD + ANIMAL) & COMIDANIMAL (COMIDA + ANIMAL) \\
\hline MEATBALLRUS (MEATBALL + WALRUS) & ALMORSEGA (ALMÔNDEGA + MORSA) \\
\hline MOSQUITOAST (MOSQUITO + TOAST) & MOSQUITORRADA (MOSQUITO + TORRADA) \\
\hline SHRIMPANZEE (SHRIMP + CHIMPANZEE) & CAMARANZÉ (CAMARÃO + CHIMPANZÉ) \\
\hline SUBWHALE (SUBMARINE SANDWICH + WHALE) & SANDUBALEIA (SANDUÍCHE + BALEIA) \\
\hline SUSHEEP (SUSHI + SHEEP) & SUSHIVELHA (SUSHI + OVELHA) \\
\hline TACODILE (TACO + CROCODILE) & TACODILO (TACO + CROCODILO) \\
\hline WATERMELOPHANT (WATERMELON + ELEPHANT) & MELANFANTE (MELANCIA + ELEFANTE) \\
\hline WILDEBEET (WILD + BEET) & BESTERRABAS (BESTA + BETERRABA) \\
\hline
\end{tabular}

Fonte: Elaborado pelos autores (2019).

Como é possível verificar, em grande parte das palavras-valise e de suas respectivas soluções em português, o processo básico de formação é a junção da parte inicial de uma palavra com a parte final de outra (ALVES, 1990; GONÇALVES, 2003). Há de se destacar, no entanto, a solução dada a meatballrus: almorsega, que, a nosso ver, não é composta de maneira tão linear (parte inicial de um vocábulo + parte final de outro vocábulo), como as demais. No processo, houve a inserção de parte de um dos vocábulos (mors-) no meio do outro (al/.../ega), um caso diferente de interposição de morfemas, que parece não ter sido abordado, ao menos pelos autores citados. Em nosso corpus, também detectamos a ocorrência de um neologismo existente, não criado para o filme, turducken, que é formado a partir de turkey + duck + chicken, algo como peru recheado com pato e frango. Nosso destaque a esse neologismo sugere a revisão da noção de palavra-valise e novos estudos 
sobre composições por meio da junção de três ou mais vocábulos, por exemplo.

Após nossa análise, pudemos notar que dos 23 JPs analisados, 20 foram traduzidos por outros JPs, 1 foi traduzido por um recurso retórico relacionado de aliteração e 2 não foram traduzidos por outro JP. De modo geral, o tradutor conseguiu manter os efeitos idiomáticos e pragmáticos do original, fazendo uso das estratégias de tradução aqui abordadas e, acima de tudo, de sua criatividade.

Os JPs resultantes da combinação de elementos verbais e visuais apresentaram dificuldades para o tradutor, uma vez que, numa obra cinematográfica, por exemplo, não é possível alterar a cena em prol da criação de um JP na língua-alvo. Há de se admitir, porém, que, embora também decorrentes da associação de elementos verbais e visuais, se comparados a outros tipos de JP, os JPs gerados a partir de palavravalise pareceram não impor grande dificuldade ao tradutor. Delabastita (1996, p. 135) explica que os casos de polissemia podem, geralmente, ser traduzidos de forma que não haja perdas significativas, mesmo que as línguas envolvidas no processo não apresentem uma relação histórica; sobretudo se comparados aos que envolvem semelhança sonora, pois são JPs baseados numa "realidade extralinguística".

\section{CONSIDERAÇÕES FINAIS}

Ao discutirmos a tradução de JPs em geral, devemos reconhecer que todo tipo de texto pode conter manipulações linguísticas nos mais variados níveis: fonológico, grafológico, morfológico, semântico, idiomático, pragmático, entre outros. Desse modo, o tradutor, diante de tantos elementos que compõem um texto, deverá também perceber essas possíveis manipulações e, na medida do possível, tentar reproduzilas. A tradução audiovisual, mais especificamente a legendagem, impõe ao tradutor cuidados especiais, uma vez que, como vimos, texto e imagem caminham juntos e dependem de restrições de tempo e espaço. Isso significa que uma solução altamente apropriada à tradução de um romance, por exemplo, não poderá ser usada na dublagem ou legendagem de um filme. 
Além disso, se a inclusão de JPs em qualquer texto pretende atrair a atenção de leitores/ouvintes e causar algum tipo de efeito, em geral, cômico; num gênero de filme como comédia de animação, sua existência é mais do que justificada e, certamente, pretende proporcionar entretenimento aos espectadores. Diante dessas exigências ou restrições linguísticas e pragmáticas, sabemos também que o tradutor de legendas nem sempre dispõe de longos prazos para a realização de uma tarefa tão árdua, oferecendo, por vezes, traduções não tão satisfatórias e desejáveis. De qualquer modo, inferimos que a maioria das soluções analisadas neste artigo são adequadas e atendem aos objetivos a que se propõem, em detrimento de nossas sugestões.

Em suma, se no texto de partida há JPs com efeito humorístico, eles deveriam ser transpostos de maneira correspondente do ponto de vista idiomático e pragmático e, diante das possíveis estratégias de tradução apresentadas por Delabastita (1996) e Gottlieb (1997), entendemos que seja possível reproduzi-los em outro idioma, de um modo ou de outro.

WordPlay ANALYSIS IN CLOUDY WITH A CHANCE OF MEATBALLS 2 SUBTITLING

\begin{abstract}
In this article, we analyze the subtitle translation of wordplays in the animated comedy Cloudy with a chance of meatballs 2. Twenty and three wordplays were collected, compared with corresponding subtitles in Brazilian Portuguese, and analyzed to verify whether the idiomatic and pragmatic effects had been somewhat preserved. Our results reveal that out of 23 wordplays, 20 were translated into other wordplays, one into a related rhetorical device of alliteration and two were not translated into wordplays. In general, the translator rendered the original wordplays as such.
\end{abstract}

KeYwords: Audiovisual translation.Wordplays. Humor. Subtitling. 
ANÁlisis de JUEGos de Palabras en subTítulos de Lluvia de ALbÓndigas 2

\section{RESUMEN}

En este artículo analizamos la traducción de subtítulos con juegos de palabras en la comedia animada Lluvia de Albóndigas 2. Se recopilaron 23 juegos de palabras, que, en seguida, fueron comparados con los subtítulos correspondientes en portugués brasileño, y, luego, analizados el fin de verificar si los efectos idiomáticos y pragmáticos habían sido, de alguna manera, preservados. Nuestros resultados revelan que 20 se tradujeron a otros juegos de palabras, uno a un dispositivo retórico relacionado de aliteración y dos no se tradujeron a juegos de palabras. En general, el traductor representó los juegos de palabras originales como tales.

Palabras Clave: Traducción audiovisual. Juegos de palabras. Humor. Subtítulos.

\section{NOTAS}

1 Citação original: "Wordplay is the general name for the various textual phenomena in which structural features of the language(s) used are exploited in order to bring about a communicatively significant confrontation of two (or more) linguistic structures with more or less similar meanings and more or less different meanings". (DELABASTITA, 1996, p. 128).

2 Citação original: "grammars will often generate phrases or sentences that can be parsed in more than one way". (DELABASTITA, 2007, p. 603).

3 As abreviações e os símbolos utilizados neste trabalho para a explicação das estratégias de tradução de JPs referem-se aos usados por Silva (2015) em sua tese de doutorado.

\section{REFERÊNCIAS}

ALVES, Ieda Maria. Neologismo - criação lexical. São Paulo: Ática, 1990.

AMARAL, Bruna Rodrigues do. Polissemia e Homonímia: uma avaliação da correlação entre acesso lexical e contexto. 2015. 161 f. Tese (Doutorado Estudos linguísticos) - Universidade Federal de Minas Gerais, Belo Horizonte, 2015 . 
AULETE, Caldas. Dicionário contemporâneo da língua portuguesa. Disponível em: http://www.aulete.com.br/index.php. Acesso em: 2 mai. 2019. CHIARO, Delia. Issues in Audiovisual Translation. In: MUNDAY, Jeremy. The Routledge Companion to Translation Studies. London/New York: Routledge, 2009, p. 141-165.

CHIARO, Delia. Verbally expressed humour on screen: Reflections on translation and reception. The Journal of Specialised Translation, v. 6, p. 198208, 2006.

CLOUDY with a chance of meatballs 2. Direção: Cody Cameron e Kris Pearn. Produção: Pam Mardsen. California: Sony Pictures Animation, 2013.

DAVIS, Kathleen. Signature in Translation. In: DELABASTITA, Dirk. (ed.). Traductio: Essays on Punning and Translation, Manchester: St. Jerome Publishing, 1997, p. 23-43.

DELABASTITA, Dirk. Introduction. Wordplay and Translation: Special Issue of 'The Translator', v. 2, n. 2, p. 127-140, 1996.

DELABASTITA, Dirk. Wordplay as a translation problem: a linguistic perspective. In: KITTEL, Harald. et al. Übersetzung Translation Traduction: an international encyclopedia of translation studies. Berlin: Walter de Gruyter, 2007, p. 600-606.

DIAZ-CINTAS, Jorge. Audiovisual Translation Today: a question of accessibility for all. Translating Today, v. 4, p. 3-5, 2005.

DORE, Margherita. The audiovisual translation of fixed expressions and idiom-based puns. In: VALERO-GARCÉS, Carmen. (ed.). Dimensions of humor: explorations in linguistics, literature, cultural studies and translation. València: Universistat de València, 2010, p. 361-386.

GIORGADZE, Meri. Linguistic features of pun, its typology and classification. European Scientific Journal, v. 2, p. 271-275, 2014.

GONÇALVES, Carlos Alexandre. Blends lexicais em português: nãoconcatenatividade e correspondência. Veredas - Rev. Est. Ling, Juiz de Fora, v.7, n.1 e n.2, p.149-167, jan./dez. 2003.

GOTTLIEB, Henrik. You Got the Picture? On the Polysemiotics of Subtitling Wordplay. In: DELABASTITA, Dirk. (ed.). Traductio: essays on punning and translation, Manchester: St. Jerome Publishing, 1997, p. 207-232.

GUEDES, Gustavo. Dicionário de expressões. Disponível em: http://www. dicionariodeexpressoes.com.br/. Acesso em: 2 mai. 2019. 
MORREALL, John. Taking Laughter Seriously. Albany: State University of New York Press, 1983.

NOGUEIRA, Ismael David; SILVA, Armando Honorio. Termos e expressões do coloquial do cotidiano da zona rural no Brasil central no século $X X$. Goiânia: Gráfica UFG, 2017.

OHASHI, K. Cloudy with a chance of meatballs 2: análise de jogos de palavras na legendagem para português brasileiro.Orientador: Adauri Brezolin.2018. 65 f. Trabalho de Conclusão de Curso (Graduação) - Escola de Comunicação, Educação e Humanidades da Universidade Metodista de São Paulo, São Bernardo do Campo, 2018.

PECKHAM, Aaron. Urban dictionary. Disponível em: https://www. urbandictionary.com/. Acesso em: 2 mai. 2019.

SILVA, Nilson Roberto Barros da. A tradução de jogos de palavras no romance $O$ xangô de Baker Street: uma revisão do quadro de estratégias de Delabastita com o auxílio da Linguística de Corpus. 2015. 208 f. Tese (Doutorado em Linguística) - FFLCH - Universidade de São Paulo, São Paulo, 2015.

TAGNIN, Stella Esther Ortweiler. A tradução de suculentos jogos de palavras, sem perder o sabor. Revista de Estudos da Linguagem, v. 23, n. 3, p. 681-693, 2015.

TAGNIN, Stella Esther Ortweiler. O humor como quebra da convencionalidade. Revista Brasileira de Linguística Aplicada, v. 5, n. 1, p. 247-257, 2005 b.

TAGNIN, Stella Esther Ortweiler. $O$ jeito que a gente diz: combinações consagradas em inglês e português. São Paulo: Disal, 2005a.

VEISBERGS, Andrejs. The contextual use of idioms, wordplay, and translation. In: DELABASTITA, Dirk. (ed.). Traductio: Essays on Punning and Translation, Manchester: St. Jerome Publishing, 1997, p. 155-176.

WEBSTER, Noah. Merriam-Webster. Disponível em: https://www. urbandictionary.com/. Acesso em: 2 mai. 2019.

Submetido em 2 de julho de 2019

Aceito em 25 de setembro de 2019

Publicado em 12 de dezembro de 2019 